Int. J. Dev. Biol. 61: 277-284 (2017)

doi: $10.1387 / \mathrm{ijdb} .160273 \mathrm{ai}$

\title{
Ocular vessel patterning in zebrafish is indirectly regulated by Hedgehog signaling
}

\author{
OMRI WEISS ${ }^{\#, 1}$, RIVKA KAUFMAN",1, EYAL MISHANI ${ }^{2}$ and ADI INBAL ${ }^{*, 1}$ \\ 1 Department of Medical Neurobiology, Institute for Medical Research - Israel-Canada, The Hebrew University- \\ Hadassah Medical School, Jerusalem, Israel; ${ }^{2}$ Cyclotron-Radiochemistry-MicroPET Unit, Hadassah Hebrew \\ University Hospital, Jerusalem, Israel
}

\begin{abstract}
The superficial ocular vasculature of the embryonic zebrafish develops in a highly stereotypic manner and hence provides a convenient model for studying molecular mechanisms that regulate vascular patterning. We have used transgenic zebrafish embryos in which all endothelial cells express enhanced Green Fluorescent Protein and small molecule inhibitors to examine the contribution of two signaling pathways, vascular endothelial growth factor (VEGF) and Hedgehog (Hh) pathways, to the development of the superficial system. We find that most, but not all vessels of the superficial system depend on VEGF signaling for their growth. Hh signaling appears to limit superficial vessel growth over the dorsal eye and is required to promote superficial vessel growth over the ventral eye. These effects of $\mathrm{Hh}$ signaling are indirect. Our initial analyses of factors that regulate growth and patterning of superficial ocular vessels suggest that early patterning events in the embryo during organogenesis stages could influence vascular patterning later on. By studying development of specific vascular systems it should be possible to identify new roles for signaling pathways in regulating vascular development.
\end{abstract}

KEY WORDS: zebrafish, ocular vasculature, Hedgehog, VEGF

\section{Introduction}

The embryonic vertebrate eye receives blood supply from two networks of blood vessels: the hyaloid system inside the eye and the choroidal vasculature on the outer surface (Saint-Geniez and D'Amore, 2004). In zebrafish, the first vessels that supply blood to the outer surface of the eye form a highly stereotypic and simple pattern, which we have named the superficial ocular vasculature (Kaufman et al., 2015). The initial pattern of superficial ocular vasculature is completed by approximately 54 hours post fertilization (hpf) and includes one vessel that serves as an artery, the nasal radial vessel (NRV), which receives blood through the cranial division of the carotid artery ( $\mathrm{CrDI}$ ). Blood is drained from the system via two veins, the dorsal radial vessel (DRV) and the ventral radial vessel (VRV), the latter also draining the hyaloid system. NRV, DRV and VRV are interconnected by the superficial annular vessel (SAV) (see Fig. 1) (Kaufman et al., 2015; Kitambi et al., 2009). The superficial ocular system begins to develop at 22-23 hpf and is entirely derived from a single venous source, the primordial midbrain channel (PMBC) (Kaufman et al., 2015).
The highly stereotypic pattern in which superficial ocular vessels of zebrafish develop begs the question of how formation of this pattern is directed. Two main processes underlie the formation of new blood vessels, namely vasculogenesis and angiogenesis. In vasculogenesis, angioblasts, the precursors of endothelial cells, coalesce at a specific region where they differentiate into endothelial cells and rearrange to form new blood vessels. In angiogenesis, new blood vessels arise from an existing vessel, either by sprouting of new vessels (sprouting angiogenesis) or by splitting of the vessel (intussusceptive angiogenesis) (Ellertsdottir et al., 2010; Heinke et al., 2012). All ocular vessels in zebrafish form by angiogenesis (Hartsock et al., 2014; Kaufman et al., 2015), whereas the PMBC, which gives rise to superficial vessels forms by vasculogenesis (Proulx et al., 2010).

\footnotetext{
Abbreviations used in this paper: $\mathrm{CrDI}$, cranial division of the carotid artery; Dpf, days post fertilization; DRV, dorsal radial vessel; eGFP, enhanced green fluorescent protein; Hh, Hedgehog; Hpf, hours post fertilization; NRV, nasal radial vessel; PMBC, primordial midbrain channel; VEGF, vascular endothelial growth factor; VRV, ventral radial vessel.
}

\footnotetext{
*Address correspondence to: Adi Inbal, Department of Medical Neurobiology, Hebrew University Medical School, Ein-Kerem, Jerusalem 9112002, Israel. E-mail: adi.inbal@ekmd.huji.ac.il;Tel: + 972-2-6757525; Fax: +972-2-6439736. iD http://orcid.org/0000-0002-5666-109X
}

\#These authors contributed equally to this work

Accepted: 10 August, 2016.

ISSN: Online 1696-3547, Print 0214-6282 
Angiogenesis is a complex process, requiring formation of sprouts at correct locations, endothelial cell proliferation, guided migration of the growing vessel and differentiation and maturation of the new vessel as artery or vein (Carmeliet, 2003). Vascular endothelial growth factor (VEGF) family of ligands and receptors (VEGFRs) is the central regulator of angiogenesis, and promotes endothelial cell proliferation, migration and arterial fate. VEGF-A signaling through VEGFR-2 (Kdr, Flk-1) is the main pro-angiogenic mechanism (Carmeliet et al., 1996; Ferrara et al., 1996; Shalaby et al., 1995), but other family members, e.g. VEGF-B, VEGF-C and VEGFR-3 (Flt-4) have also been shown to promote angiogenesis in specific contexts (Covassin et al., 2006; Jensen et al., 2015; Ober et al., 2004).

In addition to VEGF, other signaling pathways can also promote angiogenesis. The Hedgehog $(\mathrm{Hh})$ signaling pathway has been shown to promote angiogenesis upstream of VEGF expression in several contexts (Nagase et al., 2008; Pola et al., 2001), and also during arterial differentiation (Lawson et al., 2002). Hh signaling can also promote angiogenesis by acting directly on endothelial cells (Chinchilla et al., 2010; Renault et al., 2010). However, whether Hh signaling affects, either directly or indirectly, vascular patterning is currently unknown.

In this work we begin to address the question of what are the molecular signals that help to shape the superficial ocular vasculature in zebrafish. We first examine the implications of blocking VEGF signaling and find that almost all ocular vessels require VEGF signaling for their growth and early maintenance. Surprisingly, growth of vessels arising from the ventral PMBC appears independent of VEGF signaling. We then examine whether Hh signaling contributes to promoting angiogenesis upstream of VEGF. Surprisingly, we find that reduced Hh pathway activity leads to excess angiogenesis over the dorsal eye and failure of blood vessel formation over the ventral eye. The effect of loss of $\mathrm{Hh}$ signaling on superficial vessel angiogenesis is indirect and is only partially dependent on VEGF signaling.

Together, the results described in this work begin to identify signaling pathways that are required for proper formation of ocular vessels in zebrafish and raise the idea that early patterning events during organogenesis influence later-developing patterns of blood vessels.

\section{Results}

\section{VEGF signaling is required for development and early survival of most ocular vessels}

To begin to identify the mechanisms that govern patterning of superficial ocular vessels in zebrafish, we asked what signals drove growth of these vessels. VEGF signaling is known for pro- moting angiogenesis in multiple contexts; however, recent work has shown that in the trunk of zebrafish embryos, Bone Morphogenetic Signaling (BMP) signaling drove venous angiogenesis whereas VEGF signaling drove arterial angiogenesis (Wiley et al., 2011). Given that all superficial vessels are derived from a vein, the PMBC, we asked which signaling pathway drove their growth. To examine the contribution of these signaling pathways to ocular angiogenesis we used small molecule inhibitors to block VEGF or BMP signaling and analyzed the development of ocular vessels in $\mathrm{Tg}(k d r l: E G F P)$ embryos, in which all endothelial cells express EGFP under regulation of vegfr-2 promoter/enhancer elements, thus affording visualization of the vasculature in live embryos.

Ocular vessels in zebrafish begin growing around $18 \mathrm{hpf}$, starting with the hyaloid artery that later grows to form the arterial components of the hyaloid system and following with growth from the PMBC around $20 \mathrm{hpf}$ (Kaufman et al., 2015). The PMBC itself becomes apparent in $\mathrm{Tg}(\mathrm{kdrl}: \mathrm{EGFP})$ embryos only around $18 \mathrm{hpf}$. To block VEGF signaling we treated embryos with the VEGFR inhibitor SU5416, which has been shown to efficiently block angiogenesis (Fong et al., 1999; Serbedzija et al., 1999), starting at $17 \mathrm{hpf}$ (16 somite-stage) and examined vessel development at $30 \mathrm{hpf}$ and $50 \mathrm{hpf}$. Whereas in control embryos superficial vessels appeared normal at $30 \mathrm{hpf}(\mathrm{n}=6 / 6)$, in treated embryos superficial vessels completely failed to develop $(n=15 / 15)$ (Fig. 2 A,B). Moreover, $\mathrm{CrDI}$ and hyaloid vessels also did not form. By contrast, the PMBC did form and surprisingly, a rudimentary VRV was observed in the treated embryos, suggesting that PMBC and VRV formation were VEGF-independent (Fig. 2B). By 50 hpf, in SU5416-treated embryos there was no appreciable growth of dorsal superficial vessels, and the PMBC appeared to be disintegrating. In most of the embryos the VRV and a rudimentary hyaloid vein were present $(n=12 / 14)$ (Fig. 2D).

In contrast to inhibition of VEGF signaling, a similar experiment in which BMP signaling was blocked using the specific BMP inhibitor DMH1 (Hao et al., 2010) showed that blocking BMP signaling results in abnormal superficial vessel patterning, but does not inhibit the growth of these vessels or of hyaloid vessels ( $n=13 / 16)$ (Fig. $2 E, F)$.

These results suggest that ocular vessel development largely depends on VEGF signaling, however formation of vessels originating in the ventral PMBC appears to be VEGF-independent.

Next, we examined whether components of the VEGF pathway were expressed in the developing eye and ocular vessels. Expression of VEGF receptors $k d r l$ (vegfr-2) and flt-4 (vegfr-3) in the $\mathrm{PMBC}$, which gives rise to all superficial vessels, has been described (Thisse et al., 2001). We examined expression of VEGF ligands vegfaa and vegfab. vegfaa was expressed in the developing eye during stages of ocular vessel development (24 hpf and 30 hpf), with expression mostly localized in the periphery of the lens
Fig. 1. Superficial ocular vasculature in zebrafish embryos. (A) Confocal maximum projection image of ocular vessels from a live $59 \mathrm{hpf}$ $\mathrm{Tg}(\mathrm{kdrl}: \mathrm{EGFP})$ embryo. (B) Bright field image of the eye from the embryo imaged in (A). (C) Overlay of $(A, B)$ to show localization of vessels relative to eye tissues. Arrows in (A) point at the superficial annularvessel (SAV). DRV, dorsal radial vessel; $H$, hyaloid vessels; $L$, lens; NR, neural retina; NRV, nasal radial vessel; $P M B C$, primordial midbrain channel; VRV, ventral radial vessel. Lateral view, anterior to the left. Scale bar, $50 \mu \mathrm{m}$.
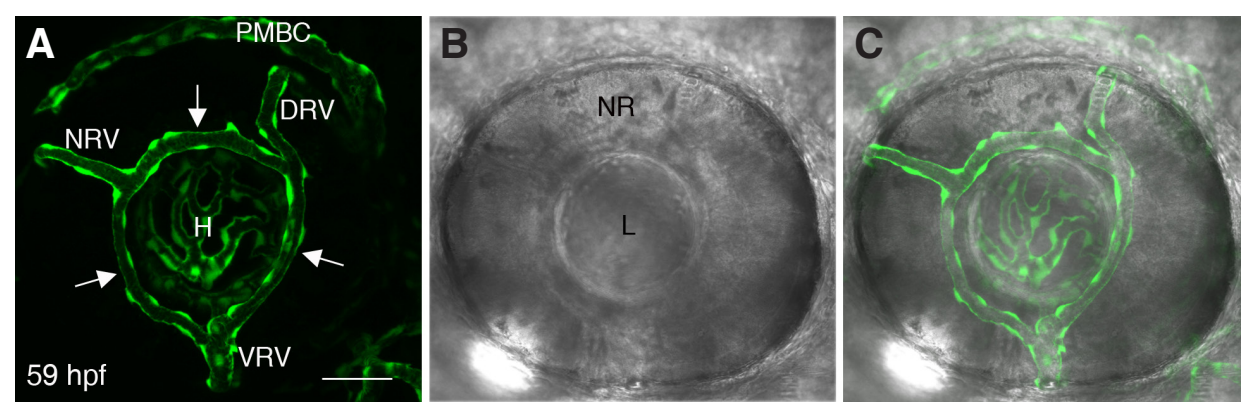

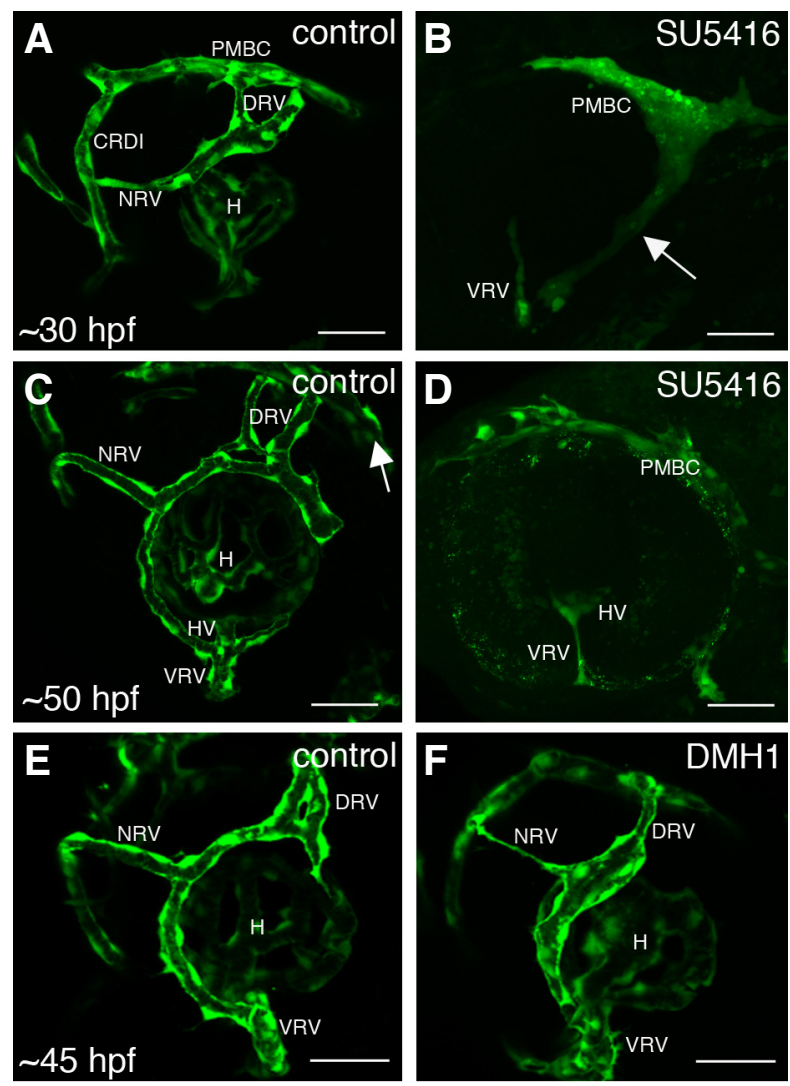

Fig. 2. Vascular endothelial growth factor (VEGF) signaling is required for superficial vasculature development. (A-D) Confocal maximum projection images of ocular vasculature in live $T g(\mathrm{kdrl}$ :EGFP) embryos treated with $1 \mu \mathrm{M}$ SU5416 from $18 \mathrm{hpf}$ (B,D) and control embryos (A,C), at 13 $(\mathbf{A}, \mathbf{B})$ and $\mathbf{( C , D )} 33 \mathrm{~h}$ after initiation of treatment and control embryo (E) or embryo treated with $10 \mu \mathrm{M} \mathrm{DMH1}$ (F) from 18 hpf. Arrow in (B) points at the optic vein that grew from the ventral $P M B C$ in a treated embryo. All panels are lateral views, anterior to the left. CrDI, cranial division of internal carotid artery; DRV, dorsal radial vessel; $H$, hyaloid vessels; HV, hyaloid vein; NRV, nasal radial vessel; $P M B C$, primordial midbrain channel; VRV, ventral radial vessel. Scale bars, $50 \mu \mathrm{m}$.
(Fig. 3 A,B). vegfab was weakly expressed in the optic (choroid) fissure region (Fig. 3 C,D). vegfc and vegfd do not appear to be expressed in or near the developing eye during the time ocular vessels develop (Astin et al., 2014; Ober et al., 2004)(our unpublished observations).

\section{VEGF signaling is required for survival of ocular vessels only at early developmental stages \\ VEGF signaling is required not only to promote angiogenesis} but also for survival of endothelial cells (Alon et al., 1995). To find whether superficial ocular vessels required VEGF signaling for their survival we treated embryos with the VEGFR-2 inhibitor 1-[4-(6,7-Dimethoxy-quinolin-4-yloxy)-3-fluoro-phenyl]-3-(2-fluorophenyl)-urea (Ilovich et al., 2008), hereafter referred to as U7, at different time windows and examined the effect on ocular blood vessels. This VEGFR-2 inhibitor was used in this work interchangeably with SU5416 and gave the same results. Ocular vasculature was documented just prior to treatment and imaged again at the end of the treatment. The first time window of treatment was between 18 and $25 \mathrm{hpf}$. At $18 \mathrm{hpf}$, ocular vessels have not formed yet and the PMBC was not detected. Only the hyaloid artery was observed beginning to grow inside the eye (Fig. 4 A,B). After blocking VEGF signaling from $18 \mathrm{hpf}$ until $25 \mathrm{hpf}$, consistent with the data described above when using SU5416, the PMBC formed but no sprouting of DRV was observed and only a rudimentary VRV could be seen $(n=7 / 7)$, whereas in control embryos the DRV has begun growing $(n=6 / 7)$ (Fig. $\left.4 A^{\prime}, B^{\prime}\right)$. Next we blocked VEGF signaling from 27 hpf, when the DRV has already sprouted (Fig. 4 C,D), until $47 \mathrm{hpf}$, a time point when in control embryos most superficial ocular vessels have already formed, including DRV, NRV, VRV and anterior SAV ( $n=11 / 11)$ (Fig. 4C'). In treated embryos, whereas at $27 \mathrm{hpf}$ a well-developed DRV was observed (Fig. 4D), at $47 \mathrm{hpf}$ almost none of the vessels could be detected, and only a remnant of the VRV was present ( $n=9 / 9$ ) (Fig. 4D'), indicating that VEGF signaling was also required for the survival of newly formed superficial vessels. Finally, we blocked VEGF signaling from $45 \mathrm{hpf}$, when much of the superficial system has formed except the posterior SAV (Fig. $4 \mathrm{E}, \mathrm{F})$ until $62 \mathrm{hpf}$, when the superficial system has fully formed. Whereas in control embryos superficial vessels have generated
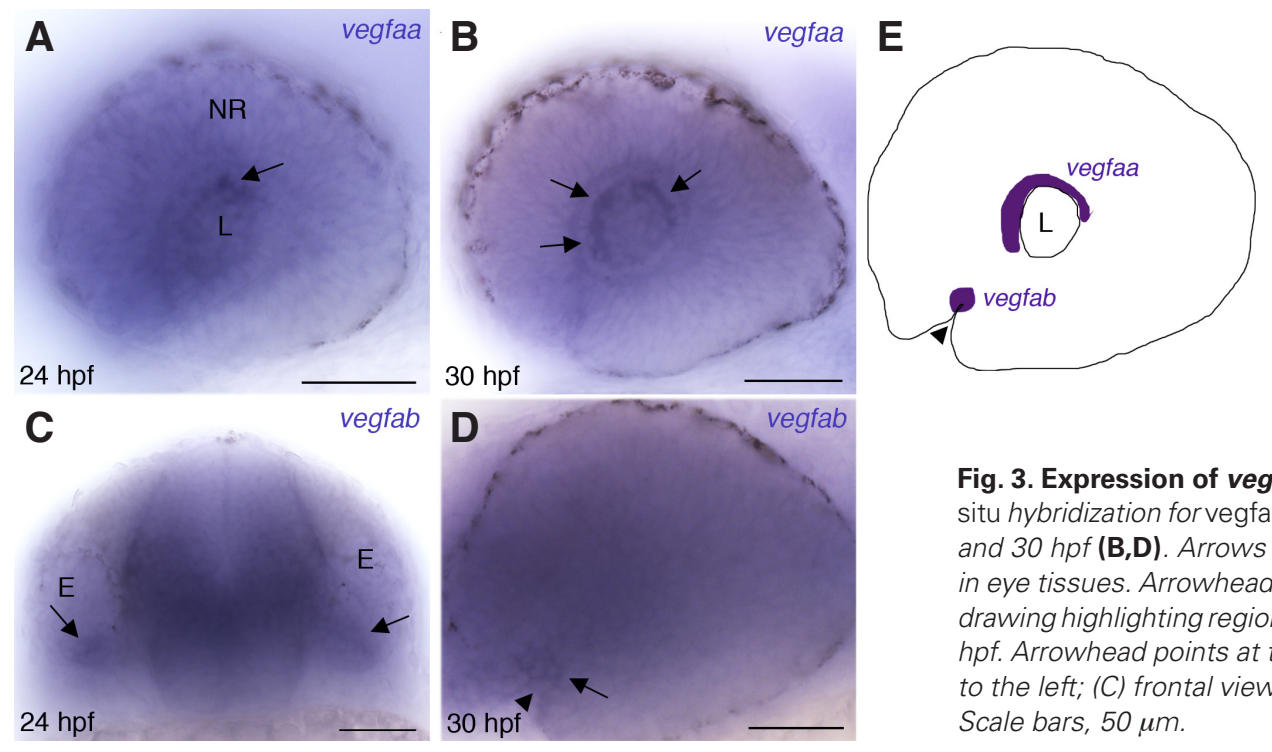

Fig. 3. Expression of vegfa ligands in developing eye tissues. (A-D) In situ hybridization for vegfaa (A,B) and vegfab (C,D) mRNAs at $24 \mathrm{hpf}(\mathbf{A}, \mathbf{C})$ and 30 hpf (B,D). Arrows point at regions where expression is observed in eye tissues. Arrowhead in (D) points at the optic fissure. (E) Schematic drawing highlighting regions of vegfaa and vegfab expression (purple) at 30 hpf. Arrowhead points at the optic fissure. $(A, B, D)$ Lateral views, anterior to the left; (C) frontal view, dorsal is up. $E$, eye; $L$, lens; NR, neural retina. Scale bars, 50 um. 

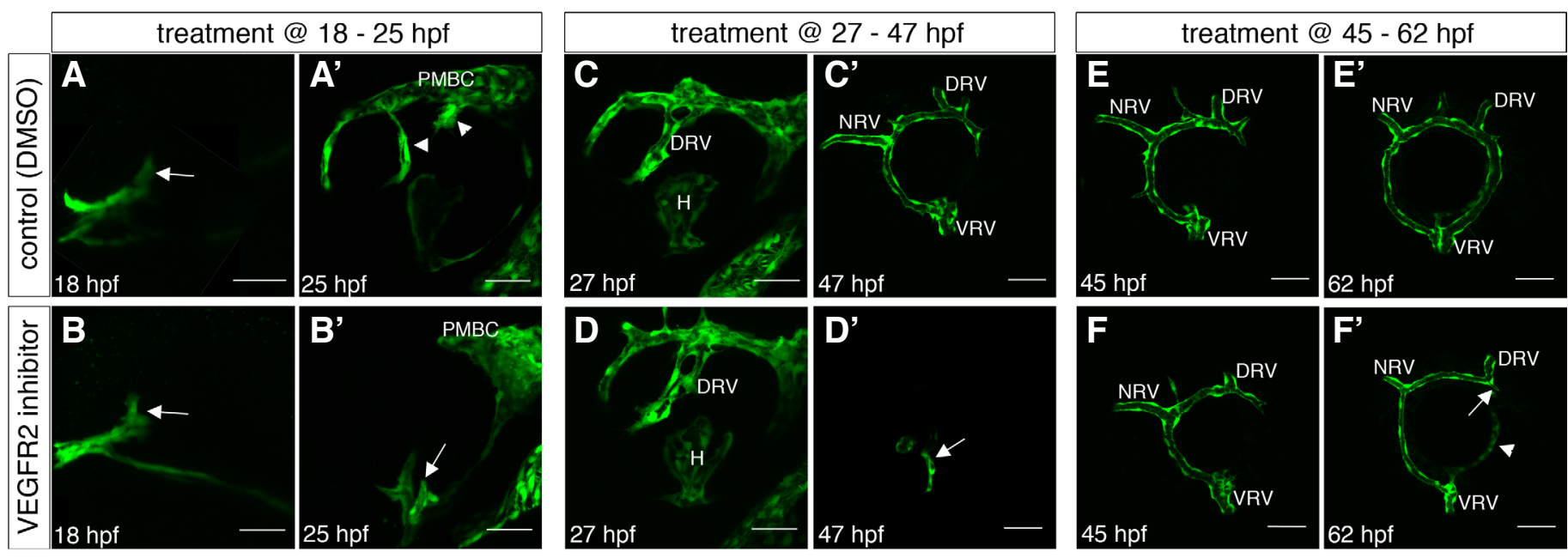

Fig. 4. Vascular endothelial growth factor (VEGF) is required for survival of newly formed superficial vessels. (A-F, $\left.A^{\prime}-F^{\prime}\right)$ Confocal maximum projection images of superficial ocular vasculature in live Tg(kdrl:EGFP) control embryos (upper panel) and embryos treated with 500 nM VEGFR-2 inhibitor U7 (lower panel) at different time windows. Time window is depicted above each panel group. In each time window group, left images are just before treatment and right images are at the end, in the same embryos and eyes. Arrows in $(\mathbf{A}, \mathbf{B})$ point at the hyaloid artery that begins growing into

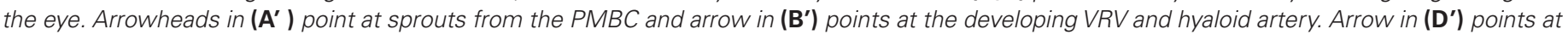
a remnant of the VRV. Arrow in (F') points at the point where growth of superficial annular vessel (SAV) was arrested and arrowhead points at a hyaloid vessel. In (C', E, E', F, F') hyaloid vessels are not shown to help focus on superficial vasculature. All panels are lateral views, anterior to the left. DRV, dorsal radial vessel; $H$, hyaloid vessels; NRV, nasal radial vessel; PMBC, primordial midbrain channel; VRV, ventral radial vessel. Scale bars, 50 um.

the final pattern $(n=7 / 7)$, in treated embryos development of the superficial system was arrested and remained as it was at 45 hpf ( $\mathrm{n}=7 / 7$ ) (Fig. 4 E',F,F'). Importantly, vessels did not degrade, suggesting that from $45 \mathrm{hpf}$ and possibly even earlier, superficial vessels no longer require VEGF signaling for their survival.

Together, the results show that consistent with known functions of VEGF signaling, it is required for the formation of most superficial ocular vasculature and for the survival of these vessels only during the stages shortly after they have formed.

\section{Loss of Hedgehog signaling results in excess sprouting from the PMBC and abnormal superficial vessel patterning}

We next asked which additional signaling pathways might influence superficial vessel development. We chose to examine the effect of Hh signaling because it has been shown to positively regulate VEGF signaling in several contexts and it also influences eye development. To find whether and how Hh signaling affected superficial vessel development we used smoothened (smo) mutant embryos, in which activity of Smoothened, the obligatory mediator of Hh signaling, is missing (Varga et al., 2001). Surprisingly, we found that in smo mutants, sprouting from the PMBC was increased. At $27 \mathrm{hpf}$, in normal embryos 1-2 sprouts from the PMBC give rise to 1-2 DRVs (Kaufman et al., 2015) (Fig. 5A). By contrast, in mutant embryos we observed up to six sprouts, which gave rise to an ectopic network of vessels over the dorsal aspect of the developing eye ( $n=19 / 19)$ (Fig. 5 B,C,F). By 54 hpf, when development of the superficial system is complete (Fig. 5D), in smo mutants the abnormally patterned ectopic network of vessels persisted over
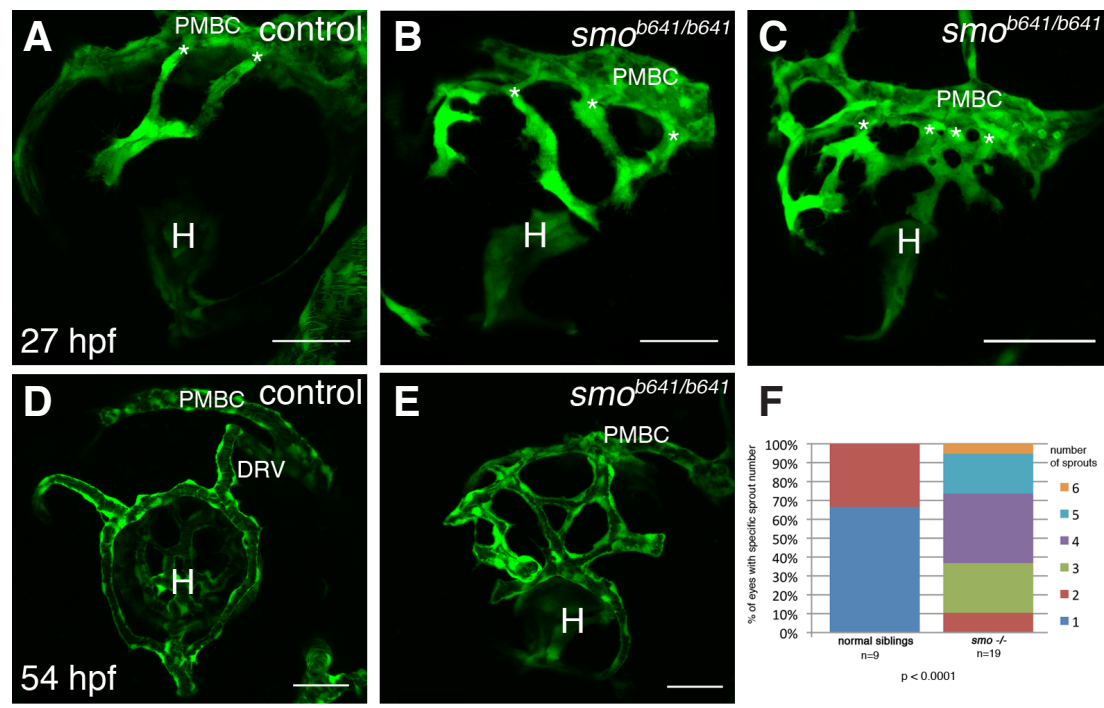

Fig. 5. Excess superficial vessel sprouting in smo mutant embryos. (A-E) Confocal maximum projection images of superficial ocular vasculature in live normal or smo mutant embryos carrying kdrl:EGFP transgene, at $27 \mathrm{hpf}$ (A-C) or 54 hpf(D,E). Asterisks in (A-C) mark exit points of sprouts from the PMBC. (F) Quantification of the number of sprouts from dorsal PMBC in smo mutants versus normal siblings at 27 hpf. The difference in the number of sprouts is statistically significant (Students's t-test). In all images, anterior is left and dorsal up. DRV, dorsal radial vessel; $H$, hyaloid vessels; PMBC, primordial midbrain channel. Scale bars, $50 \mu \mathrm{m}$. 
Fig. 6. Early cyclopamine treatment phenocopies smo superficial vessel phenotype. (A-H) Confocal maximum projection images of superficial ocular vasculature in live Tg(kdrl:EGFP) control embryos $(\mathbf{A}, \mathbf{E})$ and embryos treated with $10 \mu \mathrm{M}$ cyclopamine (cya) from different time points (B-D, F-H). Treatment start time is depicted above each pair of images from the same embryo, showing phenotypes at 27-29 hpf (top panel) and $47 \mathrm{hpf}$ (bottom panel). Arrowheads in $(A, B)$ point at sprouts from the dorsal $P M B C$ over the eye. (I-K) Quantification of the number of dorsal vessels connected to the PMBC in controlembryos and embryos treated with cyclopamine at $48 \mathrm{hpf}$. Separate comparisons are shown for each time point of cyclopamine addition (I: $10 \mathrm{hpf}$; $\mathrm{J}: 14 \mathrm{hpf} ; \mathrm{K}: 18 \mathrm{hpf})$. P values for each comparison are depicted (Students's t-test). $H$, hyaloid vasculature. All images are lateral views, anterior to the left. Scale bars, 50 um.

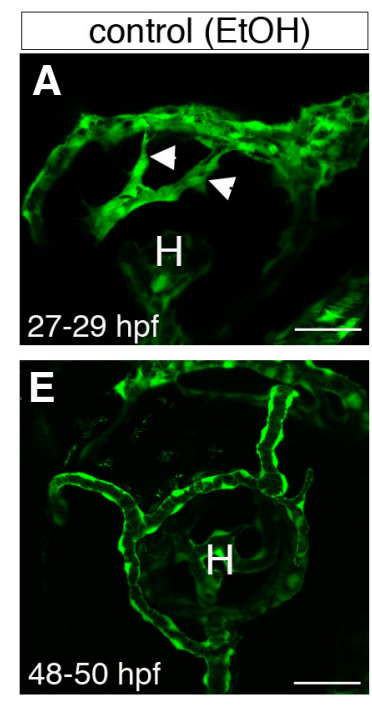

$$
\text { I }
$$

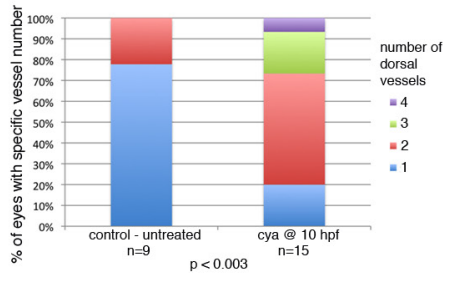

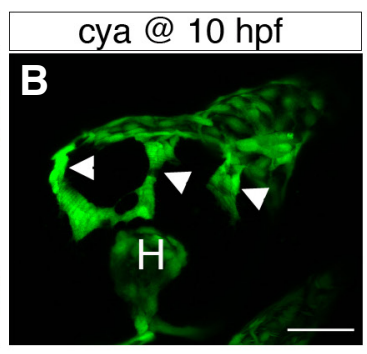
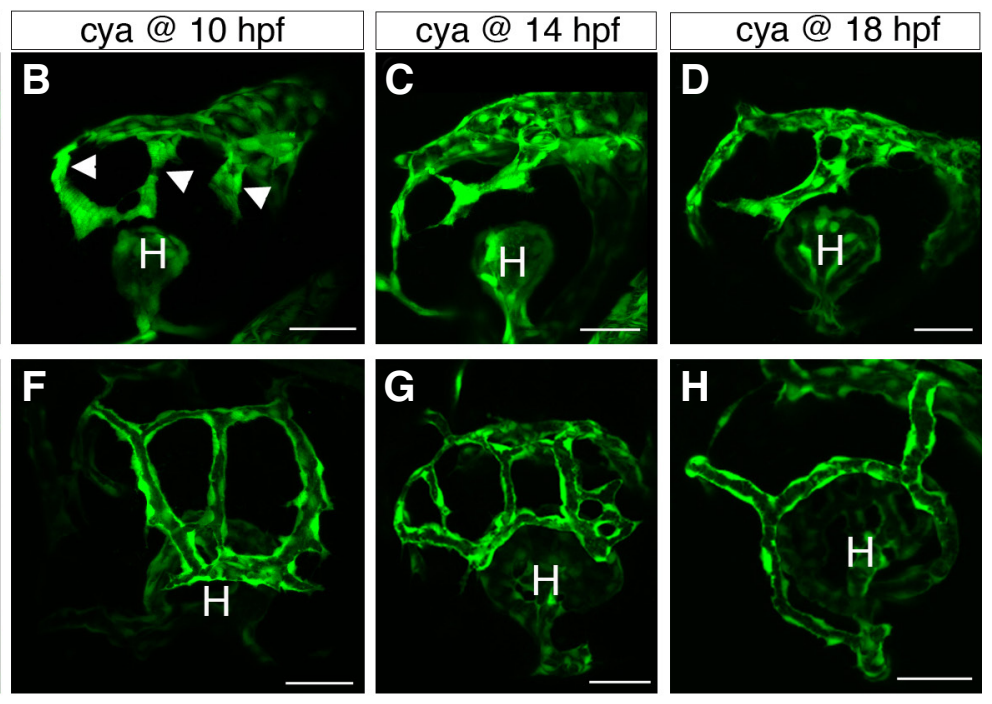

$J$

K the dorsal eye whereas vessels failed to grow over the ventral eye $(n=15 / 15)$ (Fig. 5E). Hence, in the absence of Hh activity superficial vessel patterning is abnormal, suggesting a role for Hh signaling in limiting angiogenesis from the dorsal PMBC and in promoting vascular development over the ventral eye.

\section{Hedgehog functions indirectly to influence ocular vessel patterning}

Because $\mathrm{Hh}$ ligands are not expressed near the dorsal PMBC during the time of sprouting (Ekker et al., 1995; Krauss et al., 1993), we hypothesized that the effect of Hh on ocular angiogenesis was indirect. To test this hypothesis we interfered with $\mathrm{Hh}$ signaling during different time windows and assayed development of superficial ocular vessels. The rationale of this experiment is that if $\mathrm{Hh}$ signaling directly affected vessel growth, then blocking $\mathrm{Hh}$ signaling around the time of sprouting from the PMBC would lead to a similar phenotype to smo mutants. Alternatively, if $\mathrm{Hh}$ signaling acted indirectly, then in order to phenocopy the smo mutant phenotype one would need to interfere with Hh signaling before vessel sprouting. To block Hh signaling we used the small molecule cyclopamine, which inhibits Smo function (Chen et al., 2002). For all time points of control and treatment, results represent at least 10 embryos. When embryos were treated with cyclopamine from gastrulation stages (6-10 hpf) and assayed at 27-29 hpf and at 48-50 hpf, superficial vessels showed similar phenotypes to those of smo mutants at both time points (Fig. 6 $\mathrm{B}, \mathrm{F}, \mathrm{I})$. When embryos were treated from $14 \mathrm{hpf}$ (12 somite stage), their superficial vasculature appeared relatively normal at $27-29 \mathrm{hpf}$, but phenocopied smo mutants at 48-50 hpf (Fig. $6 \mathrm{C}, \mathrm{G}, \mathrm{J})$. When treatment was initiated at $18 \mathrm{hpf}$, superficial vessels developed normally at both time points (Fig. $6 \mathrm{D}, \mathrm{H}, \mathrm{K}$ ). Since sprouting from

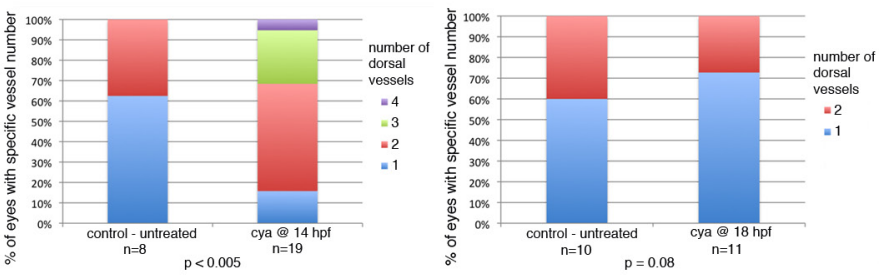

the PMBC starts only at 22-23 hpf, these data are consistent with the idea that $\mathrm{Hh}$ signaling influences sprouting and patterning of superficial vessels indirectly.

\section{Excess sprouting in smo mutants is only partially VEGF- dependent}

The excessive sprouting from the PMBC in smo mutant embryos is surprising given that, to date, $\mathrm{Hh}$ signaling was found to be proangiogenic. As Hh pathway activity can regulate VEGF expression and ocular vessel growth is largely dependent on VEGF signaling, we next asked whether and how expression of VEGF ligands was affected in smo mutants. In situ hybridization for vegfaa showed clear reduction of expression in the trunk region compared to normal (Fig. 7 B,D), as previously described (Lawson et al., 2002), however, expression levels in the head and eye region appeared much less affected (Fig. 7 A,C). vegfab expression also appeared largely unaffected in the head and eye regions (Fig. 7E,G), whereas in the trunk region it appeared somewhat elevated (Fig. 7 F,H). Hence, Hh activity does not appear to play a major role in regulating relevant VEGF pathway ligand expression in the head region.

Next, we blocked VEGF signaling in smo mutant embryos by treating them with SU5416 from $18 \mathrm{hpf}$ and assayed ocular vessel development at $30 \mathrm{hpf}$ and $50 \mathrm{hpf}$. Surprisingly, treated smo mutant embryos showed at $30 \mathrm{hpf}$ some sprouting from the PMBC over the dorsal eye, whereas their treated normal siblings, similar to treated wild-type embryos, had no sprouting (Fig. 8 B,C,G). Although sprouts were present in smo mutant embryos, they were underdeveloped compared to untreated embryos (Fig. 8B). At 50 hpf, sprouts of treated smo mutant embryos continued to develop, while treated siblings showed degeneration of vasculature. At both time points, treated smo mutant embryos had significantly 

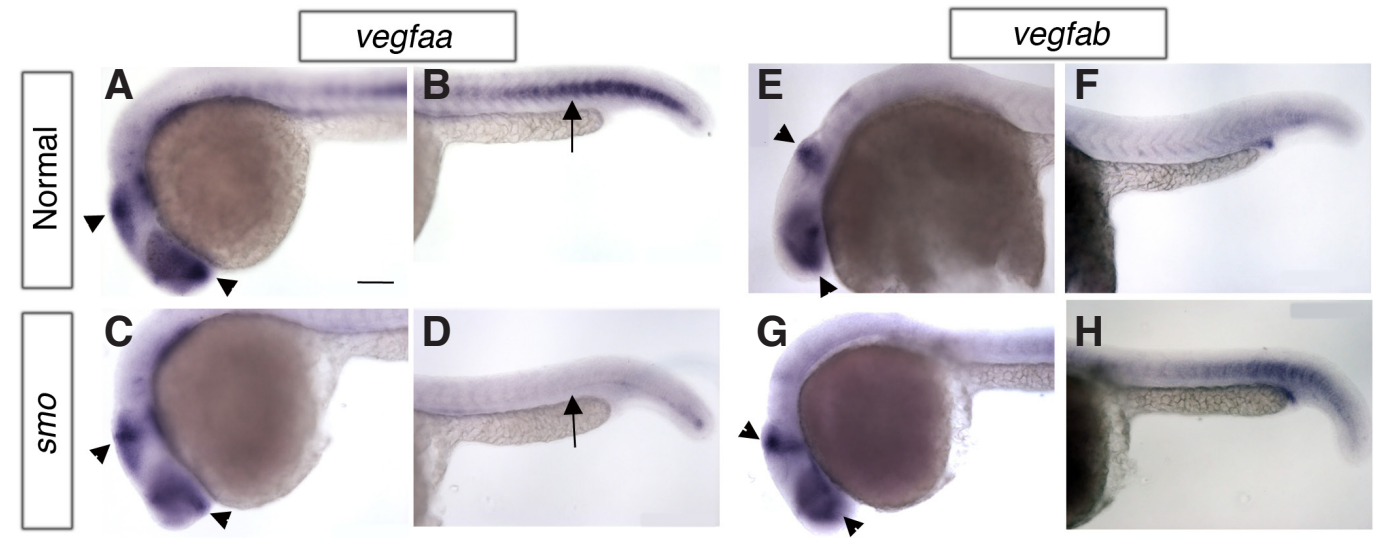

Fig. 7. vegfaa and vegfab expression in smo mutant embryos. (A-H) In situ hybridization for vegfaa $(A-D)$ and vegfab (E-H) in normal $(A, B, E, F)$ and smo mutant $(C, D, G, H)$ embryos. (A,C,E,G) show expression in the head region, $(\mathbf{B}, \mathbf{D}, \mathbf{F}, \mathbf{H})$ show expression in the trunk region. Arrowheads point at major sites of expression in the head, and arrows in $(B, D)$ point at somite region that expresses vegfaa in normal but not in smo mutant embryos. All images are lateral views, anterior to the left. Scale bar, 100 um. more sprouts than treated normal siblings, but significantly less than untreated smo mutant embryos (Fig. 8G). This result suggests that excessive sprouting in embryos lacking $\mathrm{Hh}$ signaling is only partially dependent on VEGF activity. The mechanism that enables angiogenesis when VEGF activity is blocked remains to be determined.

\section{Discussion}

In this work we examine the contributions of VEGF and Hh signaling pathways to formation and patterning of superficial ocular vessels in zebrafish. We find that VEGF signaling is required to promote growth and survival of newly formed ocular vessels, with exception of vessels that originate in the ventral PMBC. Hh signaling is not required for superficial vessels growth but is required for their correct patterning.
Although VEGF signaling is the pathway most commonly implicated in promoting angiogenesis, other signaling pathways have been shown to promote vascular growth independently of VEGF. For example, Bone morphogenetic protein (BMP) signaling has been shown to promote venous sprouting angiogenesis in the zebrafish trunk, whereas VEGF signaling promoted arterial sprouting angiogenesis (Wiley etal., 2011). However, we find that even though the entire superficial vasculature is derived from a venous source, the PMBC, it is largely dependent on VEGF for its development by angiogenesis. Only vessels derived from the ventral PMBC, i.e. the VRV and hyaloid venous vessels appear to develop independently of VEGF signaling. It is interesting to note that the growth of these vessels from the ventral PMBC appears somewhat different from angiogenesis from the dorsal PMBC as endothelial cells originating from the ventral PMBC form a thin chain of cells that reaches the ventral aspect of the eye, near the optic fissure (Kaufman et
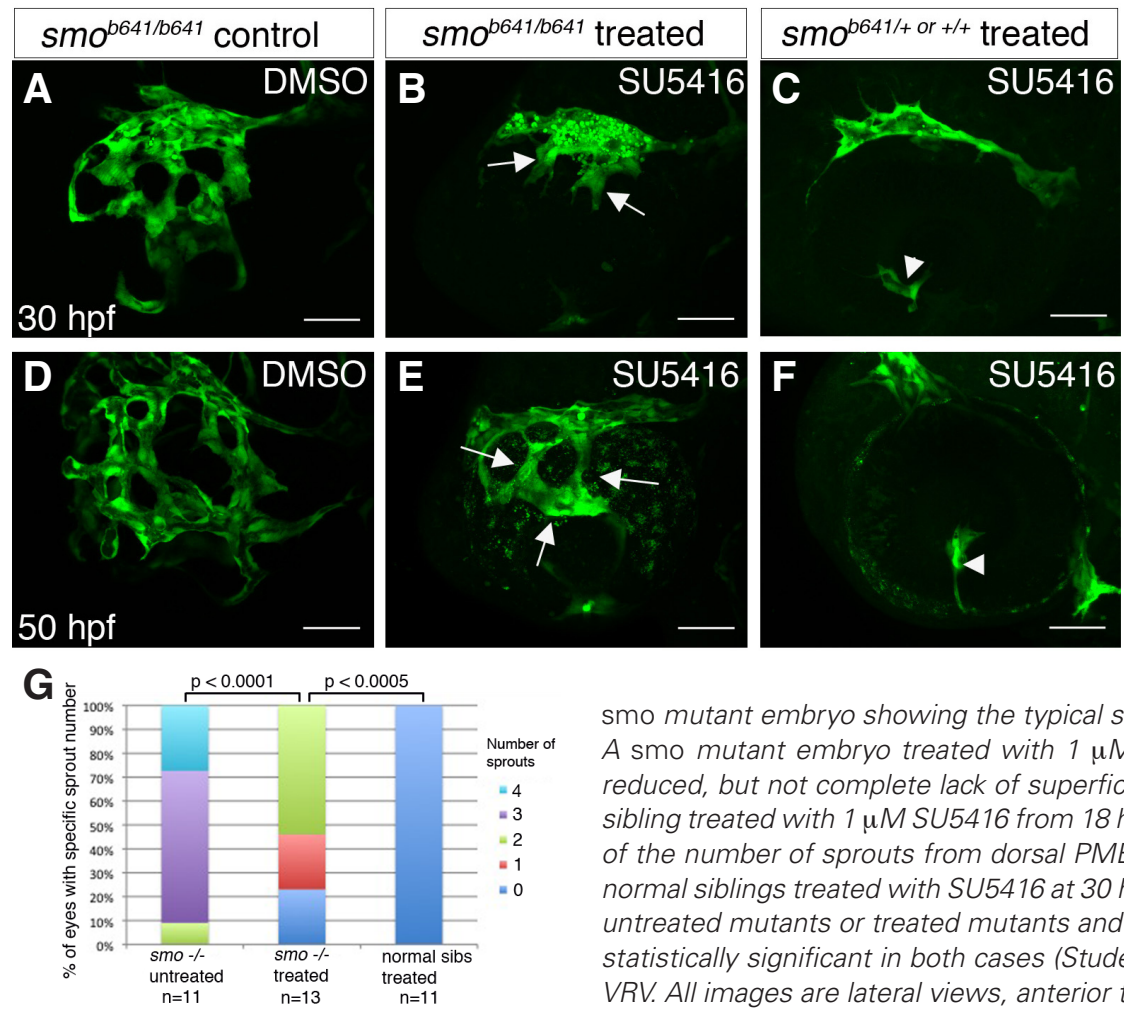
smo mutant embryo showing the typical superficial vessel phenotype of smo mutant embryos. (B,E) A smo mutant embryo treated with $1 \mu \mathrm{M}$ SU5416 from 18 hpf to inhibit VEGF signaling, showing reduced, but not complete lack of superficial vessel growth (arrows, compare to C,F). (C,F) A normal sibling treated with $1 \mu \mathrm{M}$ SU5416 from $18 \mathrm{hpf}$ showing no superficial vessel growth. (G) Quantification of the number of sprouts from dorsal PMBC in smo mutants, treated or untreated with SU5416 and normal siblings treated with SU5416 at 30 hpf. Comparing the number of sprouts between treated and untreated mutants or treated mutants and sibs shows that the difference in the number of sprouts is statistically significant in both cases (Students's t-test). Arrowheads point at residual hyaloid vein and VRV. All images are lateral views, anterior to the left. Scale bars, $50 \mu \mathrm{m}$. 
account for this growth, e.g apelin/elabela (Helker et al., 2015) and their potential role needs to be examined.

The lack of $\mathrm{Hh}$ signaling resulted in a surprising effect on ocular vessels. Given that $\mathrm{Hh}$ is known to function as a pro-angiogenic factor, we expected that if it had a role in ocular vessel development, its loss of function would lead to reduced angiogenesis. However, we observed the opposite effect over the dorsal eye, namely increased sprouting from the dorsal PMBC. Over the ventral eye vessels failed to grow, which is consistent with a pro-angiogenic role of Hh. These opposite effects are indirect, hence, they are mediated by another process that takes place by mid-late segmentation stages. One possible candidate process is eye patterning, which is largely completed by the time superficial vessels begin to form at approximately 22-23 hpf. Both dorsoventral and nasotemporal patterning of the eye are influenced by Hh signaling (Ekker et al., 1995; Hernandez-Bejarano et al., 2015; Lupo et al., 2005; Takeuchi et al., 2003). We hypothesize that the stereotypic growth of superficial ocular vessels, which takes place over the surface of the eye, is at least in part directed by the molecular landscape of the eye. If this hypothesis is correct, abnormal eye patterning could lead to abnormalities in superficial vessel patterning. Hence, it is possible that eyes of $\mathrm{Hh}$-deficient embryos, which have been shown to be abnormally patterned, mediate the effect of $\mathrm{Hh}$ signaling on superficial vessel development. Alternatively, abnormalities of other adjacent structures due to lack of Hh activity, such as brain tissues or the surface ectoderm in the eye region, could also influence ocular vessel development. At the molecular level, it is possible that factors that restrict angiogenesis such as, for example, PlexinD1 (Childs et al., 2002; Torres-Vazquez et al., 2004) are reduced in the dorsal PMBC or eye region in Hh-deficient embryos. The exact mechanism through which $\mathrm{Hh}$ influences ocular vessel patterning will likely remain unclear until better understanding of the direct signals that underlie ocular vessel patterning is achieved.

\section{Materials and Methods}

\section{Fish lines and husbandry}

Zebrafish (Danio rerio) were maintained according to standard procedures on a 14 hour light $/ 10$ hour dark cycle at $28.5^{\circ} \mathrm{C}$ and embryos were staged as previously described (Kimmel et al., 1995). The following published lines were used in this work: $\mathrm{Tg}(\mathrm{kdrl}: \mathrm{EGFP}) \mathrm{s} 843$ (Jin et al., 2005), smoothened null allele smob641 (Varga et al., 2001). AB and TL lines were used as wild type. All experiments were approved by the Hebrew University Authority for Biological and Biomedical Models.

\section{In situ hybridization}

Whole-mount in situ hybridization (WISH) using riboprobes was performed according to standard protocols (Thisse and Thisse, 2008). BM Purple (Roche) was used as color substrate.

Probes used in this work were vegfaa (Liang et al., 2001); vegfab:vegfab coding sequence was PCR amplified from wild-type total CDNA, cloned into pGEM-T Easy vector (Promega) and confirmed by sequencing. The plasmid was linearized using Ncol and RNA was transcribed using SP6 RNA polymerase.

\section{Small molecule treatments}

To block VEGF signaling we used interchangeably two VEGFR-2 inhibitors: SU5416 (Sigma-Aldrich \#S8442) was dissolved in DMSO and was used at $1 \mu \mathrm{M}$ and 1-[4-(6,7-Dimethoxy-quinolin-4-yloxy)-3-fluoro-phenyl]3-(2-fluoro-phenyl)-urea (llovich et al., 2008) was dissolved in DMSO and was used at $500 \mathrm{nM}$. DMH1 (Sigma-Aldrich \#D8946) was dissolved in
DMSO and was used at $10 \mu \mathrm{M}$. Cyclopamine (Sigma-Aldrich \#C4116) was dissolved in $\mathrm{EtOH}$ and used at $10 \mu \mathrm{M}$.

\section{Imaging}

To block pigmentation when imaging embryos older than $24 \mathrm{hpf}$, embryos were raised from $22 \mathrm{hpf}$ in the presence of $0.003 \% \mathrm{~N}$-Phenylthiourea (PTU; Sigma-Aldrich \#P7629). Live embryos were anaesthetized using tricaine and mounted in $0.5 \%$ low-melting-point agarose (SeaPlaque, Lonza).

Images were acquired using Zeiss LSM700 confocal microscope and Axio Imager.M2 compound microscope or with Discovery.V8 stereoscope and AxioCam MRc digital camera (Zeiss). Microscope objectives used were $40 \times 1.0$ NA water objective or $25 \times 0.8$ NA or $10 \times 0.3$ NA. Images were exported as JPEG or TIFF files using ZEN 2009 LE software (Zeiss) and figures were assembled using Adobe Photoshop CS4 software.

\section{Quantification and statistical analysis}

Quantification of dorsal sprouts of superficial vessels was performed by manually counting exit points of sprouts from the PMBC in 3D reconstructions of confocal image data. Statistical analysis was done using Student's t-test.

\section{Acknowledgements}

We wish to thank Ohad llovich for providing the VEGF inhibitor U7.

\section{References}

ALON, T., HEMO, I., ITIN, A., PE'ER, J., STONE, J. and KESHET, E. (1995). Vascular endothelial growth factor acts as a survival factor for newly formed retinal vessels and has implications for retinopathy of prematurity. Nat Med 1: 1024-1028.

ASTIN, J. W., HAGGERTY, M. J., OKUDA, K. S., LE GUEN, L., MISA, J. P., TROMP, A., HOGAN, B. M., CROSIER, K. E. and CROSIER, P. S. (2014). Vegfd can compensate for loss of Vegfc in zebrafish facial lymphatic sprouting. Development 141: 2680-2690.

CARMELIET, P. (2003). Angiogenesis in health and disease. Nat Med 9: 653-660.

CARMELIET, P., FERREIRA, V., BREIER, G., POLLEFEYT, S., KIECKENS, L., GERTSENSTEIN, M., FAHRIG, M., VANDENHOECK, A., HARPAL, K., EBERHARDT, C. et al., (1996). Abnormal blood vessel development and lethality in embryos lacking a single VEGF allele. Nature 380: 435-439.

CHEN, J. K., TAIPALE, J., COOPER, M. K. and BEACHY, P. A. (2002). Inhibition of Hedgehog signaling by direct binding of cyclopamine to Smoothened. Genes Dev 16: 2743-2748.

CHILDS, S., CHEN, J. N., GARRITY, D. M. and FISHMAN, M. C. (2002). Patterning of angiogenesis in the zebrafish embryo. Development 129: 973-982.

CHINCHILLA, P., XIAO, L., KAZANIETZ, M. G. and RIOBO, N. A. (2010). Hedgehog proteins activate pro-angiogenic responses in endothelial cells through noncanonical signaling pathways. Cell Cycle 9: 570-579.

COVASSIN, L. D., VILLEFRANC, J. A., KACERGIS, M. C., WEINSTEIN, B. M. and LAWSON, N. D. (2006). Distinct genetic interactions between multiple Vegf receptors are required for development of different blood vessel types in zebrafish. Proc Natl Acad Sci USA 103: 6554-6559.

EKKER, S. C., UNGAR, A. R., GREENSTEIN, P., VON KESSLER, D. P., PORTER, J. A., MOON, R. T. and BEACHY, P. A. (1995). Patterning activities of vertebrate hedgehog proteins in the developing eye and brain. Curr Biol 5: 944-955.

ELLERTSDOTTIR, E., LENARD, A., BLUM, Y., KRUDEWIG, A., HERWIG, L., AFFOLTER, M. and BELTING, H. G. (2010). Vascular morphogenesis in the zebrafish embryo. Dev Biol 341: 56-65.

FERRARA, N., CARVER-MOORE, K., CHEN, H., DOWD, M., LU, L., O'SHEA, K. S., POWELL-BRAXTON, L., HILLAN, K. J. and MOORE, M. W. (1996). Heterozygous embryonic lethality induced by targeted inactivation of the VEGF gene. Nature 380: 439-442.

FONG, T. A., SHAWVER, L. K., SUN, L., TANG, C., APP, H., POWELL, T. J., KIM, Y. H., SCHRECK, R., WANG, X., RISAU, W. et al., (1999). SU5416 is a potent and selective inhibitor of the vascular endothelial growth factor receptor (Flk-1/ KDR) that inhibits tyrosine kinase catalysis, tumor vascularization, and growth of multiple tumor types. Cancer Res 59: 99-106. 
HAO, J., HO, J. N., LEWIS, J. A., KARIM, K. A., DANIELS, R. N., GENTRY, P. R., HOPKINS, C. R., LINDSLEY, C. W. and HONG, C. C. (2010). In vivo structureactivity relationship study of dorsomorphin analogues identifies selective VEGF and BMP inhibitors. ACS Chem Biol 5: 245-253.

HARTSOCK, A., LEE, C., ARNOLD, V. and GROSS, J. M. (2014). In vivo analysis of hyaloid vasculature morphogenesis in zebrafish: A role for the lens in maturation and maintenance of the hyaloid. Dev Biol 394: 327-339.

HEINKE, J., PATTERSON, C. and MOSER, M. (2012). Life is a pattern: vascular assembly within the embryo. Front Biosci (Elite Ed) 4: 2269-2288.

HELKER, C. S., SCHUERMANN, A., POLLMANN, C., CHNG, S. C., KIEFER, F., REVERSADE, B. and HERZOG, W. (2015). The hormonal peptide Elabela guides angioblasts to the midline during vasculogenesis. Elife 4.

HERNANDEZ-BEJARANO, M., GESTRI, G., SPAWLS, L., NIETO-LOPEZ, F., PICKER, A., TADA, M., BRAND, M., BOVOLENTA, P., WILSON, S. W. and CAVODEASSI, F. (2015). Opposing Shh and Fgf signals initiate nasotemporal patterning of the zebrafish retina. Development 142: 3933-3942.

ILOVICH, O., JACOBSON, O., AVIV, Y., LITCHI, A., CHISIN, R. and MISHANI, E. (2008). Formation of fluorine-18 labeled diaryl ureas--labeled VEGFR-2/PDGFR dual inhibitors as molecular imaging agents for angiogenesis. Bioorg Med Chem 16: 4242-4251.

JENSEN, L. D., NAKAMURA, M., BRAUTIGAM, L., LI, X., LIU, Y., SAMANI, N. J. and CAO, Y. (2015). VEGF-B-Neuropilin-1 signaling is spatiotemporally indispensable for vascular and neuronal development in zebrafish. Proc Natl Acad Sci U S A 112: E5944-5953.

JIN, S. W., BEIS, D., MITCHELL, T., CHEN, J. N. and STAINIER, D. Y. (2005). CelIular and molecular analyses of vascular tube and lumen formation in zebrafish. Development 132: 5199-5209.

KAUFMAN, R., WEISS, O., SEBBAGH, M., RAVID, R., GIBBS-BAR, L., YANIV, K. and INBAL, A. (2015). Development and origins of zebrafish ocular vasculature. BMC Dev Biol 15: 18

KIMMEL, C. B., BALLARD, W. W., KIMMEL, S. R., ULLMANN, B. and SCHILLING, T. F. (1995). Stages of embryonic development of the zebrafish. Dev Dyn203: 253-310.

KITAMBI, S. S., MCCULLOCH, K. J., PETERSON, R. T. and MALICKI, J. J. (2009). Small molecule screen for compounds that affect vascular development in the zebrafish retina. Mech Dev 126: 464-477.

KRAUSS, S., CONCORDET, J. P. and INGHAM, P. W. (1993). Afunctionally conserved homolog of the Drosophila segment polarity gene hh is expressed in tissues with polarizing activity in zebrafish embryos. Cell 75: 1431-1444.

LAWSON, N. D., VOGEL, A. M. and WEINSTEIN, B. M. (2002). sonic hedgehog and vascular endothelial growth factor act upstream of the Notch pathway during arterial endothelial differentiation. Dev Cell 3: 127-136.

LIANG, D., CHANG, J. R., CHIN, A. J., SMITH, A., KELLY, C., WEINBERG, E. S. and GE, R. (2001). The role of vascular endothelial growth factor (VEGF) in vasculogenesis, angiogenesis, and hematopoiesis in zebrafish development. Mech Dev 108: 29-43.
LUPO, G., LIU, Y., QIU, R., CHANDRARATNA, R. A., BARSACCHI, G., HE, R. Q. and HARRIS, W. A. (2005). Dorsoventral patterning of the Xenopus eye: a collaboration of Retinoid, Hedgehog and FGF receptor signaling. Development 132: 1737-1748.

NAGASE, T., NAGASE, M., MACHIDA, M. and FUJITA, T. (2008). Hedgehog signalling in vascular development. Angiogenesis 11: 71-77.

OBER, E. A., OLOFSSON, B., MAKINEN, T., JIN, S. W., SHOJI, W., KOH, G. Y ALITALO, K. and STAINIER, D. Y. (2004). Vegfc is required for vascular development and endoderm morphogenesis in zebrafish. EMBO Rep 5: 78-84.

POLA, R., LING, L. E., SILVER, M., CORBLEY, M. J., KEARNEY, M., BLAKE PEPINSKY, R., SHAPIRO, R., TAYLOR, F. R., BAKER, D. P., ASAHARA, T. et al., (2001). The morphogen Sonic hedgehog is an indirect angiogenic agent upregulating two families of angiogenic growth factors. Nat Med 7: 706-711.

PROULX, K., LU, A. and SUMANAS, S. (2010). Cranial vasculature in zebrafish forms by angioblast cluster-derived angiogenesis. Dev Biol 348: 34-46.

RENAULT, M. A., RONCALLI, J., TONGERS, J., THORNE, T., KLYACHKO, E., MISENER, S., VOLPERT, O. V., MEHTA, S., BURG, A., LUEDEMANN, C. et al., (2010). Sonic hedgehog induces angiogenesis via Rho kinase-dependent signaling in endothelial cells. J Mol Cell Cardiol 49: 490-498

SAINT-GENIEZ, M. and D'AMORE, P. A. (2004). Development and pathology of the hyaloid, choroidal and retinal vasculature. Int J Dev Biol 48: 1045-1058.

SERBEDZIJA, G. N., FLYNN, E. and WILLETT, C. E. (1999). Zebrafish angiogenesis: a new model for drug screening. Angiogenesis 3: 353-359.

SHALABY, F., ROSSANT, J., YAMAGUCHI, T. P., GERTSENSTEIN, M., WU, X. F., BREITMAN, M. L. and SCHUH, A. C. (1995). Failure of blood-island formation and vasculogenesis in Flk-1-deficient mice. Nature 376: 62-66.

TAKE-UCHI, M., CLARKE, J. D. and WILSON, S. W. (2003). Hedgehog signalling maintains the optic stalk-retinal interface through the regulation of Vax gene activity. Development 130: 955-968.

THISSE, B., PLUMIO, S., FÜRTHAUER, M., LOPPIN, B., HEYER, V., DEGRAVE, A., WOEHL, R., LUX, A., STEFFAN, T., CHARBONNIER, X. Q. et al., (2001). Expression of the zebrafish genome during embryogenesis. ZFIN Direct Data Submission (http://zfin.org).

THISSE, C. and THISSE, B. (2008). High-resolution in situ hybridization to wholemount zebrafish embryos. Nat Protoc 3: 59-69.

TORRES-VAZQUEZ, J., GITLER, A. D., FRASER, S. D., BERK, J. D., VAN, N. P., FISHMAN, M. C., CHILDS, S., EPSTEIN, J. A. and WEINSTEIN, B. M. (2004) Semaphorin-plexin signaling guides patterning of the developing vasculature. Dev Cell 7: 117-123.

VARGA, Z. M., AMORES, A., LEWIS, K. E., YAN, Y. L., POSTLETHWAIT, J. H., EISEN J. S. and WESTERFIELD, M. (2001). Zebrafish smoothened functions in ventral neural tube specification and axon tract formation. Development 128: 3497-3509.

WILEY, D. M., KIM, J. D., HAO, J., HONG, C. C., BAUTCH, V. L. and JIN, S. W. (2011). Distinct signalling pathways regulate sprouting angiogenesis from the dorsal aorta and the axial vein. Nat Cell Biol 13: 686-692. 


\section{Further Related Reading, published previously in the Int. J. Dev. Biol.}

Ras-Related Nuclear Protein is required for late developmental stages of retinal cells in zebrafish eyes

Cheng-Yung Lin, Hsing-Yen Huang, Po-Nien Lu, Chien-Wei Lin, Kuang-Ming Lu and Huai-Jen Tsai

Int. J. Dev. Biol. (2015) 59: 435-442

http://www.intjdevbiol.com/web/paper/150310ht

Hedgehog signalling is required for cloacal development in the zebrafish embryo Caroline A. Parkin, Claire E. Allen and Philip W. Ingham

Int. J. Dev. Biol. (2009) 53: 45-57

http://www.intjdevbiol.com/web/paper/082669cp

Ocular forkhead transcription factors: seeing eye to eye

Holly E. Moose, Lisa E. Kelly, Srivamsi Nekkalapudi and Heithem M. El-Hodiri

Int. J. Dev. Biol. (2009) 53: 29-36

http://www.intjdevbiol.com/web/paper/072505hm

Expression of Bmp ligands and receptors in the developing Xenopus retina Jennifer C. Hocking and Sarah McFarlane

Int. J. Dev. Biol. (2007) 51: 161-165

http://www.intjdevbiol.com/web/paper/062185jh

Neural crest derivatives in ocular and periocular structures

Sophie Creuzet, Christine Vincent and Gèrard Couly

Int. J. Dev. Biol. (2005) 49: 161-171

http://www.intjdevbiol.com/web/paper/041937sc

Regulation of vertebrate eye development by Rx genes

Travis J. Bailey, Heithem El-Hodiri, Li Zhang, Rina Shah, Peter H. Mathers and Milan Jamrich Int. J. Dev. Biol. (2004) 48: 761-770

http://www.intjdevbiol.com/web/paper/041878tb

Historical perspective on the development and evolution of eyes and photoreceptors Walter J. Gehring

Int. J. Dev. Biol. (2004) 48: 707-717

http://www.intjdevbiol.com/web/paper/041900wg

Retinal homeobox genes and the role of cell proliferation in cavefish eye degeneration Allen G Strickler, Kuburat Famuditimi and William R Jeffery

Int. J. Dev. Biol. (2002) 46: 285-294

http://www.intjdevbiol.com/web/paper/12068949

Sonic hedgehog: a common signal for ventral patterning along the rostrocaudal axis of the neural tube

J Ericson, J Muhr, T M Jessell and T Edlund

Int. J. Dev. Biol. (1995) 39: 809-816

http://www.intjdevbiol.com/web/paper/8645565
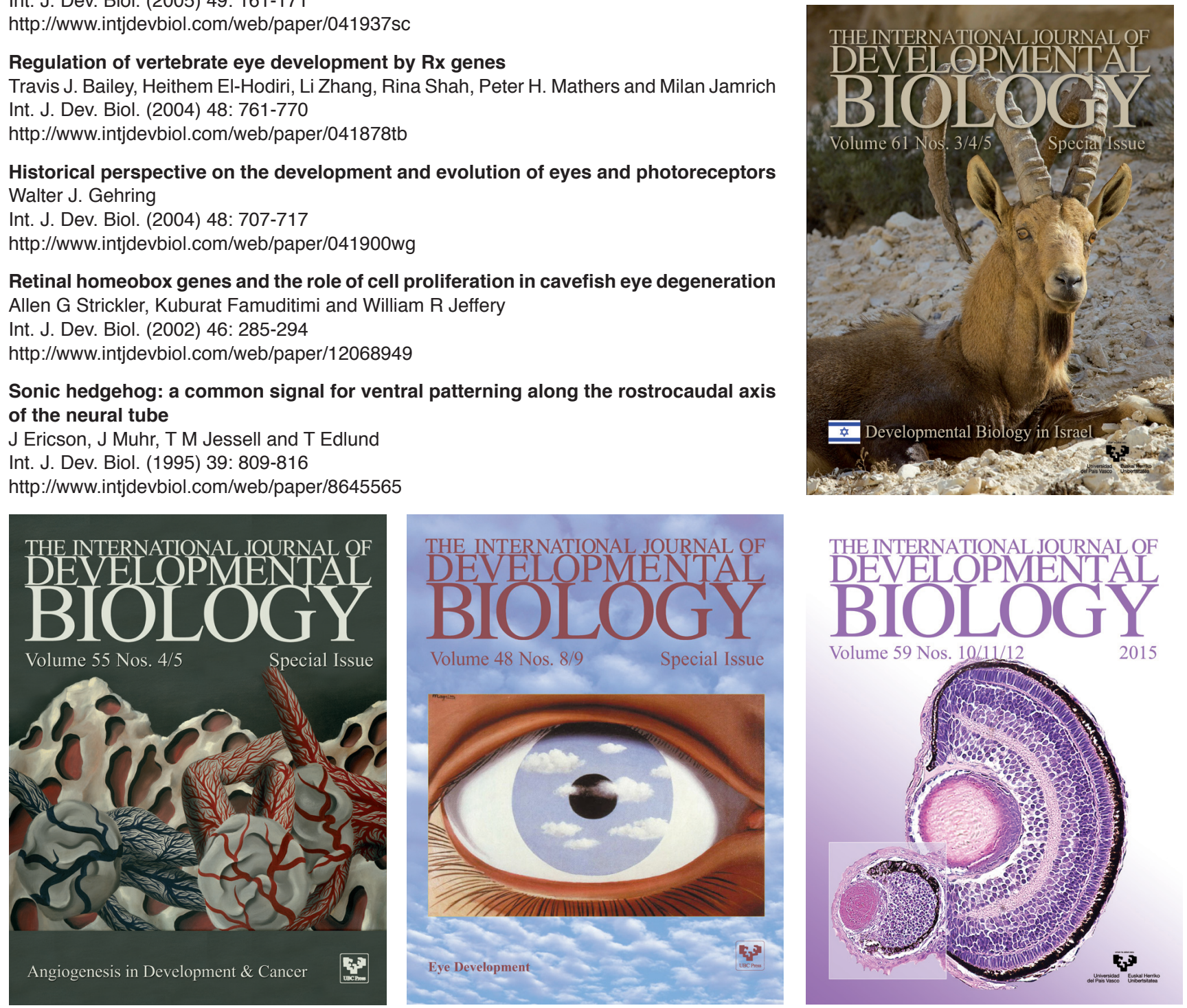